\title{
Concise Clinical Pharmacology
}

\section{Ben Greenstein and Adam Greenstein, Pharmaceutical Press, London-Chicago (First edition), 2007. ISBN 0-85369-576-8, $\mathfrak{£ 1 9 . 9 5}$}

\section{J. W. F. van Mil}

Published online: 12 September 2007

(c) Springer Science+Business Media B.V. 2007

Clinical pharmacology is an important field in pharmacy. It helps pharmacists assessing the validity of prescriptions, discussing pharmacotherapy with colleagues and physicians, and understanding pharmacotherapy in general.

The book 'Concise Clinical Pharmacology' by Green and Green indeed is concise clinical pharmacology. In its 300 pages it presents almost all aspects of body functions, drugs and diseases. It helps the reader to understand how most medicines exert their actions and how to apply this knowledge to rational pharmacotherapy. It could be that this book is less suitable for first year students because it is concise and yet comprehensive, but it certainly is very helpful for practicing (clinical and non-clinical) pharmacists. Additionally, the format $(21.5 \times 13.7 \mathrm{~cm})$ is very handy, but some people will need their reading glasses to be able to study some of the graphs.
A minor comment could be that the topics of the chapters seem to be a mixture of bodily functions, diseases and medicine types. That makes finding information not so easy, but there is a comprehensive index. The glossary of terms is also very helpful for those who are no accustomed to medical-English terminology.

A second point of criticism could be that the content of the book is very fundamental. The finer (and newer) principles of clinical pharmacology like the use of genetic information are not (yet) sufficiently discussed. There also is little general attention for drug-drug and drug-food interactions, although they constitute a large part of the drug-related problems that pharmacists must deal with in everyday practice.

In spite of these minor comments, I feel that this book can be very helpful for pharmacists in their daily practice.

J. W. F. van Mil ( $\square)$

Margrietlaan 1, Zuidlaren 9471 CT, The Netherlands

e-mail: jwfvmil@planet.nl 